\title{
Keep calm enfrenta a vergonha - contributos para um programa de competências sócio-emocionais
}

\section{Keep calm and face shame - contributes to a socio-emotional skills program}

\author{
Carolina Raposo *, Célia Barreto Carvalho **, Marina Sousa* \& Suzana Nunes Caldeira*** \\ *Universidade dos Açores, **Universidade dos Açores e Centro de Investigação do Núcleo de Estudos \\ e Intervenção Cognitivo-Comportamental, ***Universidade dos Açores - CICS.NOVA.UAçores \\ Portugal
}

\begin{abstract}
Resumo
Este estudo pretende avaliar a adequabilidade e a pertinência de uma intervenção em adolescentes ao nível da vergonha externa. Esta intervenção insere-se num programa de competências sócio-emocionais intitulado "Alinha com a Vida” que visa a promoção da Inteligência Emocional. A amostra em estudo é constituida por 229 alunos, a frequentar o $8^{\circ}$ ano de escolaridade. A investigação é de caráter qualitativo, tendo a recolha e a análise dos dados decorrido a partir da análise de conteúdo. Os resultados sugerem que os adolescentes adquiriram competências ao nível da identificação, diferenciação e conhecimento da vergonha, tendo revelado interesse e um desempenho positivo durante as atividades.

Palavras chave: adolescentes, vergonha externa; intervenção, aprendizagem.
\end{abstract}

\begin{abstract}
This study aims to assess the suitability and relevance of an intervention in adolescents at the level of other shame. This intervention is part of a socio-emotional skills program entitled "Alinha com a Vida" for the promotion of Emotional Intelligence. The study sample is composed of 229 students, attending the $8^{\text {th }}$ grade. The research is qualitative, with the collection and analysis of data passed from the content analysis. The results suggest that adolescents acquire skills in the identification, differentiation and knowledge of shame and has shown interest and a positive performance in activities.

Keywords: adolescents, other shame, intervention, learning.
\end{abstract}

A vergonha é uma emoção social transversal a todos os seres humanos e com grande importância a nível individual e interpessoal. Por esta emoção emergir de um processo autoconsciente em situações de transgressão ou fracasso, provoca uma avaliação negativa do self global e fortes implicações no ajustamento psicológico do indivíduo (Tangney, Wagner \& Gramzow, 1992).

Segundo Tangney e Dearing (2002), esta emoção desenvolve-se ao nível das experiências interpessoais precoces que ocorrem na família e/ou noutros relacionamentos significativos. Frequentemente, a vergonha surge perante ambientes sociais hostis ou quando os recursos são escassos e não existe apoio ou carinho (Irons \& Gilbert, 2005).

Não obstante a vergonha não apresentar, no campo científico, uma definição muito consensual, é reconhecido que esta abarca duas componentes chave: a vergonha externa e a vergonha interna (Gilbert \& Procter, 2006). A vergonha externa diz respeito ao modo como o indivíduo pensa que os outros o veem, isto é, está relacionada com os pensamentos e sentimentos sobre a forma como existe na mente dos outros (Gilbert, 1998b; Gilbert \& Procter, 2006). A segunda componente, designada de vergonha interna, está relacionada com a forma como o indivíduo se perceciona a si próprio perante os outros, surgindo com o desenvolvimento da autoconsciência (Lewis, 2003). O foco de atenção é o self, o que dirige a atenção para o próprio indivíduo (atenção autodirigida) que se avalia negativamente, como inadequado, frágil ou mau, falhado, sem valor e não desejado (Gilbert \& Procter, 2006). Apesar de estas componentes reportarem a definições distintas, as mesmas podem fundir-se (Gilbert \& Procter, 2006), pois se o indivíduo se perceciona como inadequado, vai esperar que os outros o vejam da mesma forma, o que significa que as cognições externas e internas da vergonha se apresentam correlacionadas (Santos, 2009).

Várias são as abordagens que confluem para auxiliar a compreensão desta emoção e a sua influência nas relações interpessoais e na terapia clínica. Nesta linha, a análise da vergonha a partir de uma perspetiva evolucionária é bastante enriquecedora, uma vez que nos permite uma melhor compreensão deste fenómeno, ao esclarecer a sua função adaptativa e funcional nas relações interpessoais. A vergonha surge quando o ser humano se sente ameaçado em interação com os outros, pela perceção de ser negativamente avaliado, o que gera sentimentos de rejeição e crítica (Gilbert, 1998b).

De acordo com esta perspetiva, a vergonha, tal como os comportamentos de submissão e a comparação social, assume-se como uma estratégia de defesa dos seres humanos e tem como função fazer face às ameaças com aqueles que se deparam durante todo o percurso de vida, permitindo-lhes enfrentar ou afastarem-se dessas mesmas ameaças (Gilbert, 1998a). Esta estratégia utilizada de modo adaptativo, permite aos seres humanos desenvolverem-se física e mentalmente de forma saudável no seu contexto social, junto dos seus pares, família e amigos. No entanto, usadas recorrentemente, tornam-se desadaptativas, podendo tornar-se perigosas, como acontece no caso da vergonha excessiva. 
A vergonha desempenha um papel fundamental na forma como o ser humano se comporta, pois determina o seu comportamento em contextos sociais, influenciando os sentimentos que desenvolve em relação a si próprio (Gilbert, 1998b; Tangney \& Dearing, 2002; Pinto-Gouveia \& Matos, 2010).

No contexto escolar, em particular, crê-se que a vergonha excessiva concomitantemente com outros indicadores, pode emergir em dificuldades de aprendizagem. Os problemas emocionais afetam os sentimentos e os comportamentos das crianças e adolescentes, sendo que que estes podem manifestar-se de forma internalizada ou externalizada. Para Roeser e Eccles (2000) as crianças e os adolescentes que apresentam um fraco desempenho escolar e atribuem isso à incompetência pessoal apresentam sentimentos de vergonha, dúvidas sobre si mesmos, baixa autoestima e distanciamento das tarefas e atividades escolares, caracterizando problemas emocionais e comportamentos internalizados. Por sua vez, os que atribuem os problemas escolares à influência externa de pessoas hostis experimentam sentimentos de raiva, distanciamento das tarefas e atividades escolares, expressando hostilidade em relação aos outros e sentimentos de frustração, inferioridade e agressividade diante do fracasso escolar (Roeser e Eccles, 2000).

A vergonha tem diferentes implicações no indivíduo, sendo que para além de influenciar os sentimentos que ele desenvolve em relação a si próprio, também contribui para a formação da sua identidade, aceitabilidade e desejabilidade social (Gilbert, 1998b; Tangney \& Dearing, 2002; Pinto-Gouveia \& Matos, 2010). A vergonha afeta, inevitavelmente, a identidade do indivíduo, pois surge relacionada com diversos aspetos do self, como o corpo, o comportamento e/ou o caráter (Gilbert, 1998b; Andrews, Qian, \& Valentine, 2002; Tangney \& Dearing, 2002; Pinto-Gouveia \& Matos, 2010).

A partir desta visão, é possível compreender que os aspectos da vergonha parecem especialmente relevantes na infância e na adolescencia, por nestas fases as competições sociais se tornarem mais intensas (Gilbert, 2003). Daí que urge a necessidade de intervir precocemente nestas fases do desenvolvimento para prevenir a génese de patologias no estado adultez do indivíduo, tais como depressão (Andrews, Quian, \& Valentine, 2002;); ansiedade (Matos \& Pinto-Gouveia, 2009); stress (Pinto-Gouveia \& Matos, 2010), entre outras.

Investigações recentes realizadas em Portugal, mais concretamente na ilha de São Miguel, da Região Autónoma dos Açores, denotam algum desajustamento psicológico por parte dos adolescentes, uma vez que revelaram uma forte tendência destes para a paranoia e altos índices de vergonha externa, autodano e ideação suicida (Nunes, 2012; Pereira, 2012).

Neste âmbito, a parcela da intervenção de que se dá conta neste estudo, destina-se a adolescentes e visa, através do programa de competências sócio-emocionais, promover a Inteligência Emocional, de modo a aumentar a flexibilidade dos adolescentes e a sua capacidade para lidar melhor com a imprevisibilidade e a mudança, transformando os obstáculos em desafios e aumentando a sua resiliência. Crê-se que a intervenção, numa ótica preventiva, das disfunções emocionais e comportamentos desajustados, pode passar pela promoção de competências sociais e emocionais, mais concretamente, pela identificação, diferenciação e regulação emocional.

\section{Método}

\section{Objetivos}

Neste estudo, como objetivo geral tem-se avaliar a adequabilidade e pertinência da $5^{\mathrm{a}}$ sessão intitulada "Keep calm enfrenta a vergonha" de um Programa de competências sócio-emocionais intitulado "Alinha com a Vida". A partir da dinâmica "A atuação das estrelas" delineou-se como objetivos específicos: a) ativar a vergonha nos adolescentes; b) identificar a vergonha em si e nos outros; c) fomentar o conhecimento da vergonha, ao nível da sua natureza e função; d) avaliar a participação dos alunos na sessão, em função do gosto/interesse/motivação; e) avaliar a participação dos alunos na sessão, em função do desempenho dos alunos (facilidades e dificuldades); f) analisar a avaliação dos alunos e professores à sessão.

\section{Participantes}

A amostra do estudo envolveu 229 alunos do $8^{\circ}$ ano de escolaridade, de ambos os sexos, de cinco escolas localizadas em Portugal, mais concretamente na ilha de S. Miguel-Açores. A amostra em estudo contou com 114 $(49,8 \%)$ alunos do sexo masculino e $115(50,2 \%)$ do sexo feminino. A idade dos participantes está compreendida entre os 13 e os 17 anos, sendo a sua média de 13,58 $(\mathrm{Dp}=0,945)$.

\section{Instrumentos}

O instrumento utilizado para compreender o impacto da intervenção "Keep calm enfrenta a vergonha" foi o Diário de Bordo, que consiste num registo de observações e experiências realizado por um determinado período de tempo, no qual se inserem ideias, expressões e interpretações (Bolivar e colaboradores, 2001, cit. in Amado, 2013). Através do Diário de Bordo o investigador regista as notas retiradas das suas observações, que segundo Bogdan e Bilken (1994, p.150) são "o relato escrito daquilo que o investigador ouve, vê, experiencia e pensa no decurso da recolha e refletindo sobre os dados de um estudo qualitativo".

O Diário de Bordo utilizado no estudo teve por base diversos registos escritos, criados a partir de alguns elementos orientadores, de acordo com os objetivos previamente definidos, nomeadamente: sessão; local; turma e o respetivo número de participantes e realização do desafio da semana, que permite a identificação da vergonha por parte dos adolescentes. Foram, ainda, elaboradas duas fichas de avaliação da sessão que facultaram mais elementos para avaliar: o impacto das sessões nos alunos e a consolidação dos conhecimentos dos alunos ao nível do reconhecimento da emoção trabalhada. 


\section{Procedimentos}

\section{Procedimetos de Recolha de Dados}

Previamente à implementação do programa "Alinha com a Vida", foi obtida a sua aprovação da Direção Regional da Educação (DRE) e, em seguida, a autorização para a realização do estudo junto dos Diretores de cada escola, bem como o consentimento informado de todos os Encarregados de Educação. O programa foi implementado em grupo, em contexto de sala de aula, na presença dos professores responsáveis pela disciplina de Cidadania. Antes de iniciar a intervenção, os alunos foram informados acerca da natureza do estudo, bem como foram respondidas todas as questões ou dúvidas expostas. Para além do consentimento informado, foi também assegurado o caráter voluntário da participação, o anonimato e a confidencialidade dos dados, assim como a liberdade de desistência a qualquer momento. A intervenção teve início no princípio de janeiro de 2014, tendo a duração de quatro meses, em regime semanal, e cada sessão com uma duração de 90 minutos.

\section{Pocedimentos de Análise de Dados}

Os dados qualitativos recolhidos através do Diário de Bordo foram sujeitos à análise de conteúdo categorial. Após repetidas leituras e consultas, procedeu-se à categorização e codificação dos dados, de forma a sistematizar e reduzir a informação para facilitar a interpretação dos resultados (Denzin \& Lincoln, 2000).

Com o objetivo de analisar a pertinência e a adequabilidade da intervenção implementada procedeu-se a uma categorização emergente, uma vez que não foram definidas categorias à priori, mas sim a partir da análise dos dados obtidos (Bardin, 2013). Após a leitura dos dados recolhidos criaram-se as seguintes categorias: "Ativação da vergonha"; "Identificação da vergonha"; "Função adaptativa da vergonha"; "Crenças associadas à vergonha na pré-intervenção"; "Crenças associadas à vergonha na pós-intervenção"; "Participação dos alunos na $5^{\mathrm{a}}$ sessão"; "Desempenho dos alunos na $5^{\mathrm{a}}$ sessão"; "Avaliação dos alunos à $5^{\mathrm{a}}$ sessão"; "Avaliação dos professores à $5^{\mathrm{a}}$ sessão".

\section{Procedimentos de Intervenção}

O programa "Alinha com a Vida" inscreve-se numa perspetiva preventiva e promocional, subscrevendo a premissa de que os programas de intervenção em contexto escolar devem englobar todos os adolescentes e não apenas a população alvo sinalizada com problemas, de modo a transformar estas aprendizagens em algo essencial para a sua educação (Martins, 2012).

O programa visa a promoção de competências sociais e emocionais e tem como objetivo desenvolver a Inteligência Emocional nos adolescentes. Pretende-se desenvolver nos adolescentes competências que permitam aumentar a sua flexibilidade, de modo a que consigam lidar melhor com a imprevisibilidade e a mudança, transformando os obstáculos em desafios e aumentando a sua resiliência. Este programa é constituído por 10 sessões, cada uma com uma duração de 90 minutos. Genericamente através deste programa pretendem-se alcançar alguns objetivos específicos, como sejam: a) fomentar o conhecimento das emoções básicas e secundárias; b) promover a capacidade para identificar emoções básicas e secundárias em si e nos outros; c) ativar formas adequadas e positivas de lidar com os diferentes estados emocionais; d) promover a automotivação, a empatia e a assertividade, considerando o seu papel facilitador do sucesso e da adaptação à vida; e e) treinar a aplicação de competências sócio-emocionais, enquanto ferramentas importantes de resiliência e na prevenção de comportamentos de risco. $\mathrm{Na}$ sessão em análise neste trabalho ( $5^{\mathrm{a}}$ sessão), como já referido pretende-se: a) ativar a vergonha nos adolescentes; b) identificar a vergonha em si e nos outros; c) fomentar o conhecimento da vergonha, ao nível da sua natureza e função; d) avaliar a participação dos alunos na sessão, em função do gosto/interesse/motivação; e) avaliar a participação dos alunos na sessão, em função do desempenho dos alunos (facilidades e dificuldades); f) analisar a avaliação dos alunos e professores à sessão.

\section{Resultados}

Ao analisarmos a categoria "Ativação da vergonha", que visa avaliar o reconhecimento em si próprio da vergonha pelos adolescentes, verifica-se que $87,39 \%$ dos adolescentes mencionaram sentir "vergonha", pois vivenciaram diferentes reações fisiológicas, como o "corar da face" (31,53\%), a vontade de expressar um "sorriso constante" (15,77\%), os "tremores" (15,77\%), o "aumento do ritmo cardíaco" (15,32\%) e o "calor" $(10,36 \%)$. Para além das reações fisiológicas os adolescentes referiram que no momento que vivenciaram a vergonha, foram despertadas distintas reações cognitivas, sendo a sua maioria, relacionada com o fato de estarem expostos aos colegas de turma ("estão a olhar para mim" - 61,26\%) e por estarem perante a possibilidade de serem avaliados pelos colegas ("o que estão a pensar de mim" - 24,32\%). É ainda importante mencionar que $22,97 \%$ dos adolescentes sentiram "alegria", bem como "ansiedade" (14,41\%) e "medo" $(4,05 \%)$, aquando da realização da dinámica.

De modo a analisar o reconhecimento da vergonha pelos adolescentes, através da categoria "Identificação da vergonha", observa-se que $24,88 \%$ dos adolescentes conseguiram identificar tanto "em si" como "nos outros" esta emoção.

Quanto à avaliação dos adolescentes face à aquisição de conhecimentos sobre a função da vergonha, através da categoria "Função adaptativa da vergonha", conclui- se que $37,84 \%$ acredita que a função da vergonha é "proteger de comportamentos e atitudes". Relativamente à análise da aquisição de conhecimentos sobre a natureza da vergonha, verifica-se, através da categoria "Crenças associadas à vergonha na pré-intervenção", que $45,45 \%$ dos adolescentes acredita que a vergonha surge quando temos receio do que os outros "estão a pensar de nós" e $27,27 \%$ dos alunos defenderam que a vergonha "é não ser capaz de...". Ainda tendo em conta a análise da aquisição de conhecimentos sobre a natureza da vergonha, verifica-se através da categoria "Crenças associadas à vergonha na pós-intervenção" que apenas 
4,05\% dos adolescentes acredita ser desvantajoso sentir vergonha, pois se não a sentissem poderiam "fazer tudo à frente de todos", bem como "apresentar trabalhos sem vergonha" (1,80\%). Pelo contrário 54,95\% dos adolescentes acredita que é vantajoso sentir vergonha, pois esta tem a função de "impedir comportamentos" $(54,95 \%)$ e permite ao indivíduo "seguir em frente" perante os obstáculos (10,81\%). Contudo, $72,73 \%$ dos adolescentes acredita que esta emoção, quando sentida excessivamente é prejudicial para o indivíduo, porque "ficamos sozinhos", e ainda 27,27\% dos alunos afirma que esta "evita-nos de fazer muitas coisas" e "leva ao suicídio e a doenças".

Com relação ao estudo da "Participação dos alunos na $5^{\text {a }}$ sessão" verifica-se, que durante a sessão foram manifestos alguns sinais de gosto/interesse/motivação por parte dos alunos. Em todas as turmas foi unânime a expressão "gostei muito desta sessão" por parte dos adolescentes (100\%). Verificou-se, ainda, que $71,64 \%$ dos adolescentes aderiram ao desafio da semana, isto é, realizaram-no apesar de este ser de carácter voluntário.

Em conformidade com os resultados acima encontrados, surgem resultados positivos quanto ao "Desempenho dos alunos na $5^{a}$ sessão", uma vez que se observou que "todos os grupos realizaram as atividades solicitadas" (100\%). Para além disso, 54,56\% dos "participantes responderam às questões sem manifestar dificuldade (e.g. não apresentaram dúvidas quanto ao que se pretendia com as perguntas da ficha, respondendo às mesmas sem precisar de ajuda por parte da dinamizadora; conseguiram compreender todo o vocabulário e foram capazes de justificar as suas respostas)". Não obstante todos estes indícios de facilidade, foram também registadas algumas "dificuldade". Em 45,45\% das turmas há registos de que "alguns alunos manifestaram-se reticentes à realização da dinâmica "A Atuação das estrelas", por sentirem vergonha".

No que respeita à categoria referente à "Avaliação dos alunos à $5^{\text {a }}$ sessão" observou-se que $87,84 \%$ dos adolescentes referiram que "não mudava nada na sessão", o que pode estar relacionado com a percentagem de adolescentes que gostaram da "dinâmica da atuação das estrelas" (51,35\%).

Por último, em relação à análise do feedback dos professores sobre a utilidade da sessão para os alunos, constata-se, através da categoria "Avaliação dos professores à $5^{a}$ sessão", que na ótica dos docentes a sessão contribuiu para que os alunos "reconhecessem em si e nos outros a vergonha" (100\%). Para além disto, os profesores reconheceram que os alunos "demonstraram interesse e participaram na sessão" $(100 \%)$ e que foram implementadas "boas estratégias" $(72,73 \%)$, capazes de provocar "alteração de comportamentos/atitudes nos alunos" (36,36\%).

\section{Discussão}

Refletindo sobre os resultados obtidos, presume-se que os adolescentes adquiriram competências ao nível da identificação, diferenciação e conhecimento emocional, o que demonstra que os materiais pedagógicos criados são pertinentes e adequados à população adolescente.
Ao analisarmos a categoria " Ativação da vergonha" verifica-se que um dos objetivos propostos nesta investigação foi alcançado, mais concretamente o objetivo "a) ativar a vergonha" nos adolescentes, pois $87,39 \%$ dos adolescentes assume ter sentido vergonha aquando a dinâmica "A Atuação das Estrelas", o que pode ser confirmado pelas reações fisiológicas ("corar" da face, o "sorriso constante", os "tremores", o "aumento do ritmo cardíaco" e o "calor") e cognitivas ("estão a olhar para mim" e "o que estão a pensar de mim") mencionadas pelos adolescentes nos seus registos. Estes dados vão ao encontro da literatura, na medida em que, para Darwin (1872/65, cit. in Gilbert, 1998b), o aparecimento da vergonha resulta de dois componentes: a reflexão sobre si mesmo de alguma característica de aparência pessoal e o pensamento sobre o que os outros pensam de si. Observam-se ainda na subcategoria "reações cognitivas", alguns pensamentos resultantes da interiorização de regras sociais ("se eu dançasse com uma rapariga era melhor"), o que comprova o fato de esta emoção ser autoconsciente (Santos, 2009).

Por a vergonha resultar da exposição social (Tangney \& Dearing, 2002) é compreensível que os adolescentes tenham afirmado sentir não só vergonha, mas também "medo" e "ansiedade", durante a dinâmica, devido à possibilidade de serem avaliados pelos colegas. Os adolescentes afirmam, ainda, ter sentido "alegria", o que poderá estar relacionado com o cariz entusiástico da dinâmica.

Relativamente à categoria "Identificação da vergonha", verifica-se que os adolescentes conseguiram identificar com alguma facilidade a emoção vergonha tanto em si $(24,88 \%)$ como nos outros $(24,88 \%)$. Este fato pode estar relacionado com o sofrimento que a vergonha provoca no indivíduo, por esta emoção ser capaz de ativar rapidamente reações fisiológicas, o que facilita a identificação da mesma não só "em si” como "nos outros" (Gilbert, 1998b; Carvalho, 2009). Através dos resultados obtidos, acredita-se que os adolescentes adquiriram capacidades ao nível do reconhecimento emocional, fato reforçado pelos registos realizados por todos os professores, e onde se pode observar o reconhecimento de que os alunos "reconhecem em si e nos outros a vergonha". Tendo esta investigação o objetivo de "b) identificar a vergonha em si e nos outros", este conjunto de resultados é um forte indicador do alcance do mesmo.

Face à categoria "Função adaptativa da vergonha", contata-se que, $37,84 \%$ dos adolescentes defende que a vergonha tem a função de proteger o indivíduo, pois evita a manifestação de determinados comportamentos e atitudes (e.g. "proteger de comportamentos e atitudes"), evitando a rejeição e a exclusão social, tal como defende Melo (2005)

De um modo geral, acredita-se que os adolescentes compreenderam a função da vergonha, uma vez que a maioria reconheceu os benefícios de a sentir $(76,57 \%)$. Apenas, 4,05\% dos adolescentes acredita que seria benéfico viver sem vergonha. Admite-se, por isso, que foram desenvolvidas nos adolescentes capacidades ao nível da identificação, diferenciação, conhecimento e regulação emocional, as quais, constituindo-se objetivos 
desta sessão, fazem com que a observação do seu incremento nos adolescentes seja uma forte evidência para que se possa afirmar a adequabilidade e a pertinência da sessão desenvolvida. Por a sessão destinada a trabalhar as emoções sociais ter sido apenas uma, optou-se por intervir afincadamente na identificação, diferenciação e conhecimento das emoções, deixando de lado a fomentação de estratégias de regulação emocional. Contudo, tal como defende Vaz (2009), estes processos influenciam-se mutuamente, o que leva a crer que se tenham conseguido avanços ao nível da regulação emocional da vergonha. Para Vaz (2009) identificar eficazmente uma emoção permite diferenciar a emoção identificada de outra. Saber identificar e diferenciar as emoções permite um bom conhecimento emocional, o qual, por sua vez, favorecerá uma boa regulação emocional. Neste sentido, para adotar estratégias de regulação emocional adequadas às situações, é necessário conseguir, não só, identificar, mas também, diferenciar as emoções implicadas (Vaz, 2009).

Através da categoria "Crenças associadas à vergonha na pré-intervenção", verifica-se que, antes da intervenção, a maioria dos adolescentes conhecia a natureza da vergonha (e.g. "estão a pensar de mim"), o que está relacionado com o fato de esta emoção ser transversal a todos os indivíduos (Tangney, 2002). Contudo, apesar de os adolescentes já adquirem este conhecimento, revelaram alguma dificuldade em compreender o benefício de sentir vergonha. Esta constatação torna-se evidente pela observação dos resultados obtidos na análise de conteúdo da categoria "Crenças associadas à vergonha na pós-intervenção", mais propriamente na subcategoria "Desvantagens da vergonha" $(4,05 \%)$.

Por outro lado, os adolescentes compreenderam que a vergonha, pode ser prejudicial à sobrevivência do indivíduo, quando sentida excessivamente, pois provoca o isolamento (e.g. "ficamos sozinhos") e a exclusão social (e.g. "quando não somos aceites nos outros grupos"), podendo também "leva[r] ao suicídio e a doenças" e a "muda[nças] (n)a nossa maneira de ser. O que vai ao encontro das conclusões de vários autores (Tangney \& Dearing, 2002; Tracy, Robins \& Tangney, 2007) que acreditam que a vergonha provoca um intenso sofrimento intrapsíquico e está associada a patologias como a depressão, ansiedade e stress.

Sendo, também, objetivo desta investigação “c) fomentar o conhecimento da vergonha, ao nível da sua natureza e função" pode-se confirmar através deste conjunto de resultados a adequabilidade e pertinência da sessão desenvolvida.

Através da categoría "Participação dos alunos na $5^{\mathrm{a}}$ sessão" verifica-se, que os adolescentes revelaram interesse pela sessão, pois $71,64 \%$ realizou o "desafio da semana", apesar de este ser de carater voluntário. Por outro lado, e ainda tendo em conta a análise da mesma categoria denota-se que $100 \%$ dos adolescentes afirmaram "gostei muito desta sessão", o que parece estar relacionado com os resultados encontrados na categoría "Desempenho dos alunos na $5^{\text {a }}$ sessão", uma vez que $100 \%$ dos alunos realizaram as tarefas propostas. Assim sendo, verifica-se que os alunos responderam muito positivamente a este programa de intervenção, o que favoreceu um ambiente de sala de aula mais afável e propício ao trabalho e à aprendizagem. Parece-nos que este fato foi fundamental para a aquisição de aprendizagens por parte dos alunos, dado que a motivação é um aspeto importante do processo de aprendizagem em sala de aula, pois a intensidade e a qualidade do envolvimento exigido para aprender dependem dela (Cavenaghi, 2009). O estudante motivado mostra-se envolvido de forma ativa no processo de aprendizagem, com esforço, persistência e até entusiasmo na realização das tarefas, desenvolvendo competências e ultrapassando desafios (Guimarães e Boruchovitch, 2004, cit. in Cavenaghi, 2009).

Em relação à categoria "Avaliação dos alunos à $5^{\text {a }}$ sessão" acredita-se que de um modo geral os adolescentes tiveram um bom desempenho nas atividades, o que é sustentado pelas diminutas dificuldades apresentadas no decorrer da intervenção e por os materiais pedagógicos desenvolvidos terem sido avaliados positivamente pelos alunos, uma vez que $87,84 \%$ dos adolescentes afirma "não mudava nada" nas sessões. Este fato pode estar relacionado com a forte motivação demonstrada pelos adolescentes, uma vez que a motivação melhora o desempenho do indivíduo e do grupo (Coda, 1995).

Alusivo à categoría "Avaliação dos professores à $5^{\mathrm{a}}$ sessão" verifica-se que os mesmos consideram que a sessão contribuiu para o desenvolvimento de competências nos adolescentes, o que sustenta a eficácia da mesma. Acredita-se que a sessão foi uma mais-valia, não só para os adolescentes como também para os professores, uma vez que no contexto escolar, os professores são os principais líderes emocionais dos seus alunos. A capacidade do professor para captar, compreender e regular as emoções dos alunos é o melhor índice do equilíbrio emocional do seu grupo (Martins, 2012).

Em síntese, parece-nos pertinente destacar o facto de se poder afirmar, com base nos resultados obtidos, que a intervenção foi pertinente e adequada ao público-alvo. Verifica-se não só que os alunos adquiriram competências ao nível da identificação, diferenciação, conhecimento e regulação emocional, como também, revelaram interesse e um bom desempenho durante a sessão. Relativamente aos professores verifica-se que igualmente, creem na pertinência e adequabilidade dos materiais criados.

\section{Conclusão}

Pela análise de conteúdo, verificou-se que a $5^{\mathrm{a}}$ sessão foi uma mais-valia para os adolescentes. Após analisar os dados obtidos, podemos concluir que a intervenção foi adequada e pertinente para o público-alvo, na medida em que os adolescentes adquiriram competências ao nível da identificação, diferenciação, conhecimento e regulação emocional. Para esta aquisição ter sido evidente, parecem ter contribuído o empenho e o entusiasmo dos adolescentes ao longo da sessão.

Através dos dados obtidos neste estudo, acredita-se terem sido criados materiais úteis para a prevenção de eventuais disfunções emocionais e comportamentos 
desajustados. Apesar de o presente estudo evidenciar resultados positivos, apresenta algumas limitações sobre as quais interessa refletir. $\mathrm{O}$ facto de a amostra ter sido selecionada de modo não aleatório pode originar algumas dificuldades em generalizar os dados para a população.

Por outro lado, por a intervenção ao nível da vergonha ter sido pontual, não foram focadas as estratégias de regulação emocional inerentes a esta emoção. Todavia, acredita-se que os adolescentes acabaram por adquirir competências a este nível, porque adquiriram competências face à identificação, diferenciação e conhecimento das emoções.

Apesar das limitações encontradas, o nosso estudo contribuiu para aumentar o conhecimento acerca da promoção de competências emocionais, ao nível da vergonha, sendo esta uma área pouco estudada em Portugal. Assim sendo, este estudo denota um caráter inovador, pois as intervenções ao nível das emoções na adolescência são escassas, apesar de ser consensual a influência da vergonha no ajustamento psicológico dos adolescentes. Neste âmbito, esta intervenção parece ser o primeiro dos muitos passos necessários para a prevenção de disfunções emocionais e comportamentos desajustados, que surgem, maioritariamente, na adolescência.

No todo, acredita-se na adequabilidade, interesse e relevância, da intervenção "Alinha com a Vida", fazendo crer que após uma melhoria de aspetos referentes ao desenho da investigação, este pode constituir-se como uma mais-valia para futuras investigações $\mathrm{e}$ intervenções, nomeadamente na construção de um manual de dinâmicas para a promoção de competências emocionais em adolescentes, destinado, não só a toda a comunidade educativa, mas também a pais, psicólogos, animadores socioculturais, entre outros, que lidam de perto com adolescentes e com todas as disfunções emocionais e comportamentos desajustados que surgem nesta fase.

\section{Referências}

Amado, J. (2013). Manual de Investigação Qualitativa em Educação. Coimbra: Imprensa da Universidade de Coimbra.

Andrews, B, Qian, M. \& Valentine, J.D. (2002). Predicting depressive symptoms with a new measure of shame: The Experience of Shame Scale. British Journal of Clinical Psychology, 41, 29-42. doi: 10.1348/014466502163778

Bardin, L. (2013). Análise de conteúdo. $4^{\mathrm{a}}$ Edição. Lisboa: Edições 70.

Bogdan, R., \& Biklen, S. (1994). Análise de conteúdo. Investigação qualitativa em educação: Uma introdução à teoria e aos métodos. Porto: Porto Editora.

Carvalho, C. (2009). Psicose Esquizofrénica. Crenças Paranóides: exploração da sua Etiologia na população normal e em doentes com esquizofrenia. Dissertação de Doutoramento não publicada, Faculdade de Psicologia e de Ciências da Educação, Universidade de Coimbra, Coimbra, Portugal.

Cavenaghi, A. (2009). Uma perspectiva autodeterminada da motivação para aprender língua estrangeira no contexto escolar. Ciências \& Cognição, 14 (2), 248-261.

Coda, R. (1995). Psicodinâmica da vida organizacional: Motivação e Liderança. São Paulo: Atlas.

Denzin, N., Lincoln Y. (2000). Handbook of qualitative research. Thousand Oaks, CA: Sage.

Gilbert, P. (1998a). Evolutionary - psychopathology: Why isn't the mind designed better than it is? British Journal of Medical Psychology, 71, 353-401. doi: 10.1111/j.2044-8341.1998.tb00998.x

Gilbert, P. (1998b). What is shame? Some core issues and controversies. In Gilbert, P. \& Andrews B. (Eds), Shame: Interpersonal behavior, psychopathology and culture (3-36). New York: Oxford University Press.

Gilbert, P. (2003). Evolution, social roles, and the differences in shame and guilt. Social Research, 70, 1205-1230. Recuperado de International Security e Counter Terrorism Reference Center.

Gilbert, P., \& Procter, S. (2006). Compassion mind training for people with high shame and self-criticism: overview and pilot study of a group therapy approach. Clinical Psychology and Psychotherapy, 13, 353-379. doi: $10.1002 / \mathrm{cpp} .507$

Irons, C., \& Gilbert, P. (2005). Evolved mechanisms in adolescent anxiety and depressive symptoms: the role of the attachment and social rank systems. Journal of Adolescence, 28, 325-341.

doi: 10.1016/j.adolescence.2004.07.004

Lewis, M. (2003). The role of the self in shame. Social Research, 70 (4), 1181-1204.

Martins, M. (2012). “À Descoberta ...” Um programa de promoção de competências sociais e emocionais. Dissertação de Mestrado não publicada, Departamento de Ciências da Educação, Universidade dos Açores, Ponta Delgada, Portugal. Recuperado de https://repositorio.uac.pt/bitstream/10400.3/2045/1/Di ssertMestradoMonicaSofiaAmaralMartins2013.pdf

Matos, M., \& Pinto-Gouveia, J. (2009). Shame as a traumatic memory. Clinical Psychology and Psychotherapy. doi: 10.1002/cpp.659.

Melo, A. (2005). Emoções no período escolar: estratégias parentais face à expressão emocional $e$ sintomas de internalização e externalização da criança. Dissertação de Mestrado não publicada, Instituto de Educação e Psicologia, Universidade do Minho, Braga, Portugal. Recuperado de http://repositorium.sdum.uminho.pt/bitstream/1822/4926 /1/TESE\%20MESTRADO\%20ANA\%20MELO.pdf

Nunes, C. (2012). Auto-dano e ideação suicida na população adolescente. Aferição do Questionário de Impulso, Auto-dano e Ideação suicida na Adolescência (QIAIS-A). Dissertação de Mestrado não publicada, Ciências da Educação, Universidade dos Açores, Ponta Delgada, Portugal. Recuperado de https://repositorio.uac.pt/bitstream/10400.3/1985/1/Di ssertMestradoCarolinaPortugalSousaNunes2013.pdf

Pereira, V. (2012). A ideação paranoide na adolescência. Um Enfoque Comunitário. Dissertação de Mestrado não publicada, Ciências da Educação, Universidade dos Açores, Ponta Delgada, Portugal. 
https://repositorio.uac.pt/bitstream/10400.3/1953/1/Di ssertMestradoVeraLuciaCoutoPereira2013.pdf

Pinto-Gouveia, J., \& Matos, M. (2010). Can shame memories become a key to identity? The centrality of shame memories predicts psychopathology. Applied Cognitive Psychology. doi: 10.1002/acp.1689. doi: 10.1002/acp.1689

Roeser, R.W., \& Eccles, J.S. (2000). Schooling and mental health. In A.J. Sameroff, M. Lewis, \& S.M. Miller (Orgs.), Handbook of developmental psychopathology (pp. 135-156). New York: Kluwer Academic/Plenum Publishers.

Santos, A. S. (2009). Diferenças individuais na tendência para a vergonha e culpa: antecedentes motivacionais. Dissertação de Mestrado não publicada, Fcauldade de Psicologia e de Ciências da Educação, Universidade de Lisboa, Lisboa, Portugal. Recuperado de http://core.ac.uk/download/pdf/12422433.pdf

Tangney, J. P., Wagner, P., \& Gramzow, R. (1992). Proneness to shame, proneness to guilt, and psychopathology. Journal of Abnormal Psychology, 101, 469-478. Doi: 10.1037/0021-843X.101.3.469

Tangney, P., \& Dearing, L. (2002). Shame and Guilt. New York: Guilford Press.

Tangney, J. P. (2002). Self-conscious emotions: The self as a moral guide. In A. Tesser, D. A. Stapel, \& J. V. Wood (Eds.), Self and motivation: Emerging psychological perspectives (97-117). Washington DC: American Psychological Association.

Tracy, J. L., Robins, R. W., \& Tangney, J. P. (2007). The self-conscious emotion: Theory and Research. New York: Guilford Press.

Vaz, F. J. (2009). Diferenciação e Regulação Emocional na Idade Adulta: Tradução e Validação de Dois Instrumentos de Avaliação para a População Portuguesa. Dissertação de Mestrado não publicada, Instituto de Educação e Psicologia, Universidade do Minho, Braga, Portugal. Recuperado de http://repositorium.sdum.uminho.pt/bitstream/1822/98 98/1/tese.pdf 